\title{
Reconstruction of head impacts in FIS World Cup alpine skiing
}

\author{
Sophie Elspeth Steenstrup, ${ }_{1}^{1}$ Kam-Ming Mok ${ }_{1}^{2}$ Andrew S McIntosh, ${ }^{3}$ Roald Bahr, \\ Tron Krosshaug ${ }^{1}$
}

- Additional material is published online only. To view please visit the journal online (http://dx.doi.org/10.1136/ bjsports-2017-098050).

${ }^{1}$ Oslo Sports Trauma Research Center, Department of Sports Medicine, Norwegian School of Sport Sciences, Oslo, Norway ${ }^{2}$ Department of Orthopaedics and Traumatology, Faculty of Medicine, Prince of Wales Hospital, The Chinese University of Hong Kong, Hong Kong, China

${ }^{3}$ Australian Centre for Research into Injury in Sport and its Prevention (ACRISP), Federation University Australia, Ballarat, Victoria, Australia

\section{Correspondence to}

Sophie Elspeth Steenstrup, Oslo Sports Trauma Research Center, Department of Sports Medicine, Norwegian School of Sport Sciences, 0806 Oslo, Norway; s.e.steenstrup@nih.no

Accepted 30 October 2017 Published Online First 25 November 2017

\section{ABSTRACT \\ Introduction Prior to the 2013/2014 season, the} International Ski Federation (FIS) increased the helmet testing speed from 5.4 to $6.8 \mathrm{~m} / \mathrm{s}$ for alpine downhill, super-G and giant slalom. Whether this increased testing speed reflects head impact velocities in real head injury situations on snow is unclear. We therefore investigated the injury mechanisms and gross head impact

biomechanics in seven real head injury situations among World Cup (WC) alpine skiers.

Methods We analysed nine head impacts from seven head injury videos from the FIS Injury Surveillance System, throughout nine WC seasons (2006-2015) in detail. We used commercial video-based motion analysis software to estimate head impact kinematics in two dimensions, including directly preimpact and postimpact, from broadcast video. The sagittal plane angular movement of the head was also measured using angle measurement software.

Results In seven of nine head impacts, the estimated normal to slope preimpact velocity was higher than the current FIS helmet rule of $6.8 \mathrm{~m} / \mathrm{s}$ (mean $8.1( \pm$ SD 0.6) $\mathrm{m} / \mathrm{s}$, range $1.9 \pm 0.8$ to $12.1 \pm 0.4 \mathrm{~m} / \mathrm{s})$. The nine head impacts had a mean normal to slope velocity change of $9.3 \pm 1.0 \mathrm{~m} / \mathrm{s}$, range $5.2 \pm 1.1$ to $13.5 \pm 1.3 \mathrm{~m} / \mathrm{s}$. There was a large change in sagittal plane angular velocity (mean $43.3 \pm 2.9 \mathrm{rad} / \mathrm{s}$ (range $21.2 \pm 1.5$ to $64.2 \pm 3.0 \mathrm{rad} / \mathrm{s})$ ) during impact.

Conclusion The estimated normal to slope preimpact velocity was higher than the current FIS helmet rule of $6.8 \mathrm{~m} / \mathrm{s}$ in seven of nine head impacts.

\section{INTRODUCTION}

Based on data from the International Ski Federation (FIS) Injury Surveillance System (ISS) at the alpine World Cup (WC) level, head injuries represent $8 \%-10 \%$ of all injuries that require medical attention. ${ }^{12}$ These injury data cover a period during which helmet use has been mandatory in all FIS WC events. ${ }^{3}$ However, helmets may not always offer optimal protection because of (A) intrinsic aspects of helmet performance, which are reflected in the helmet standards, (B) user error, for example, selection of a poorly fitting helmet or failure to properly fasten and secure the helmet, and (C) unique characteristics of the crash situation.

Prior to 2013/2014, alpine WC helmets had to comply with either European Standard (EN) 1077 (class A: giant slalom, super-G and downhill; class B: slalom) or American Society for Testing and Materials (ASTM) F2040 as minimum standards. ${ }^{4}$ The EN 1077 test standard's testing pass/ fail criterion is peak linear maximum acceleration of $250 \mathrm{~g}\left(g_{\max }<250 \mathrm{~g}\right)$ in a drop test at $5.4 \mathrm{~m} / \mathrm{s}$ onto a flat anvil. ${ }^{5}$ In comparison, the pass/fail criterion for the ASTM F2040 standard is $300 \mathrm{~g}$ peak linear acceleration $\left(g_{\max }<300 g\right)$ in a drop test at $6.2 \mathrm{~m} / \mathrm{s}$ onto a flat anvil. ${ }^{6}$ While the EN 1077 standard only includes drop tests on a flat anvil, the ASTM F2040 standard also includes drop tests on hemispherical and hazard anvils. ${ }^{5}$ Commencing prior to the 2013/2014 WC season, FIS enforced a new helmet testing rule for alpine giant slalom, super-G and downhill. ${ }^{3}$ Under the new, stricter rule, helmets must be certified to both ASTM 2040 and EN 1077 (class A) standards. In addition, the helmets are required to pass an added specific test using the EN 1077 impact energy attenuation test method with an impact speed of $6.8 \mathrm{~m} / \mathrm{s}$, which corresponds to a drop height of $2.4 \mathrm{~m} .{ }^{4}$ At present, this new and stricter rule has not been enforced by FIS for slalom. ${ }^{4}$ In slalom, the helmets have to comply with EN 1077 class B or ASTM F2040. ${ }^{4}$

Helmets are commonly assessed in impacts against rigid surfaces (mainly steel anvils), which are similar to roads or pavements, and not against more compliant surfaces such as snow. ${ }^{7}$ These unyielding test surfaces are not necessarily designed only to simulate real-world conditions; they are also a prerequisite for a rugged and repeatable impact test and cause the helmet to be the primary energy attenuating object in the test system. ${ }^{7}$ Therefore, future helmets should be developed and evaluated with regard to realistic impact conditions, including impact speed(s) and surfaces, such as snow and ice. ${ }^{8}$

The current direction in helmet development and testing is to consider the capacity of helmets to manage the head's angular kinematics (acceleration and/or velocity).$^{8-10}$ At present, angular kinematic management is not considered in any national or sports-specific standard, except through general construction requirements that consider surface characteristics and external projections. Therefore, it is of interest to describe angular kinematics during helmeted realworld impacts in as much detail as possible, with the data obtained from this video analysis.

The study aims were: (1) to describe the injury mechanisms in a selection of head impact injury cases meeting our inclusion criteria among WC alpine skiers, (2) to describe the gross head impact biomechanics, and (3) to compare the head impact kinematics with relevant helmet standards.

\section{METHODS}

\section{Case selection and video processing}

All cases among men and women in the FIS ISS from WC and Olympic Winter Games (OWG) competitions for the period 2006-2015 were reviewed for 


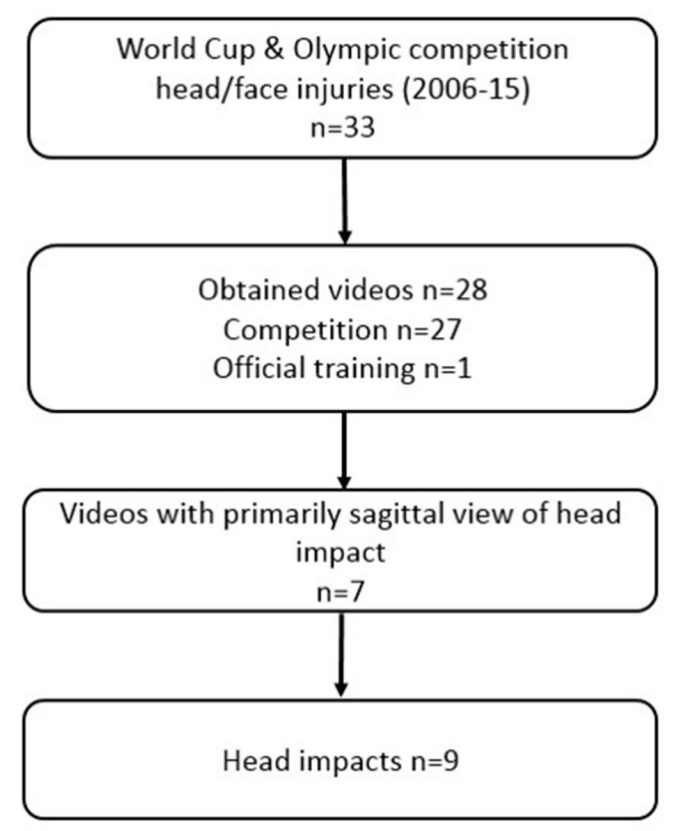

Figure 1 Flow chart of the video acquisition process.

head/face injuries. ${ }^{1211}$ This resulted in a total of 33 cases, where 27 videos were obtained and reviewed for suitability. In addition, we obtained one video from an official WC training run. In total, we therefore obtained 28 videos (figure 1 ).

In order to obtain valid velocity estimates, we required a primarily sagittal view of the athlete during the incident. Of the 28 videos obtained, only 7 met this criterion (figure 1 ).

Of the seven suitable videos, two cases had two head impacts. In the remaining cases, the athlete had one head impact, allowing us to analyse nine head impacts from seven cases.

All seven videos had an interlaced scan with frame rates of 25 and $30 \mathrm{~Hz}$, making it possible to double the effective frame rates to 50 and $60 \mathrm{~Hz}$. Videos were edited and deinterlaced using Adobe premiere Pro CS6 (Adobe Systems, San Jose, CA). The video display resolution was $1024 \times 576$ for cases 1 and 7 ; $704 \times 480$ for case 2 ; and $788 \times 576$ for cases $3-6$.

\section{Analysis of gross head impact injury mechanisms}

The injury videos were viewed frame by frame by all authors to analyse the skiing situation and gross body biomechanics preinjury, in addition to analysing the head impact in detail. Image sequences of the injury situations and qualitative descriptions of the gross injury mechanisms were compiled based on agreement between all authors.

\section{Linear kinematic analysis}

A commercial software program for video-based movement analysis (SkillSpector, V.1.3.2, Odense, Denmark) was used to digitise a fixed point on the helmet, as well as two reference points in the surroundings. We created a local calibration frame that was oriented with axes along and normal to the slope of the surface during the head impact. We assumed that the vertical direction of the video footage was aligned with the true vertical axis. The local calibration frame was positioned at the frame of head impact using the length of the skis for scaling. The measurement of the skis was performed at the closest possible frame to the frame of impact where we could see the ski perpendicularly and in full length. In three head impacts (case 1-impact 1 , case 4, case 6-impact 1), the measurement frame was the same as the calibration frame. For the remaining six head impacts, we could not see the ski perpendicularly and in full length during the head impact frame, and the measurement frame was therefore different from the calibration frame. The mean time from the measurement frame to the calibration frame for these six impacts was $0.13 \mathrm{~s}$. The ski lengths ranged from 210 to $216 \mathrm{~cm}$, corresponding to a range from 78 to 268 pixels (mean 172), with corresponding pixel lengths ranging from 0.4 to $1.3 \mathrm{~cm}$ (mean $0.8 \mathrm{~cm}$ ). We obtained actual ski dimensions from the athlete or their ski supplier.

We used a smoothing spline algorithm with a $15 \mathrm{~Hz}$ cut-off to calculate the head velocity. ${ }^{12}$ To determine the change in linear velocity in the normal to slope and along slope directions, we extracted variables from preimpact and postimpact frames, immediately before and after (maximum four frames $(80 \mathrm{~ms})$ ) the helmet impact (figure 2). The lowest downward velocity immediately preimpact was reported, in addition to the highest upward velocity immediately postimpact (figure 2 ).

\section{Error assessment}

We performed three digitising trials for each case and we report the mean \pm SD of the three trials. As a measure of the intrarater digitising error, we calculated the root mean square error $(\mathrm{cm})$ of the helmet position (normal and along slope) between the three digitising trials for all nine head impacts, and report the mean.
Impact 1

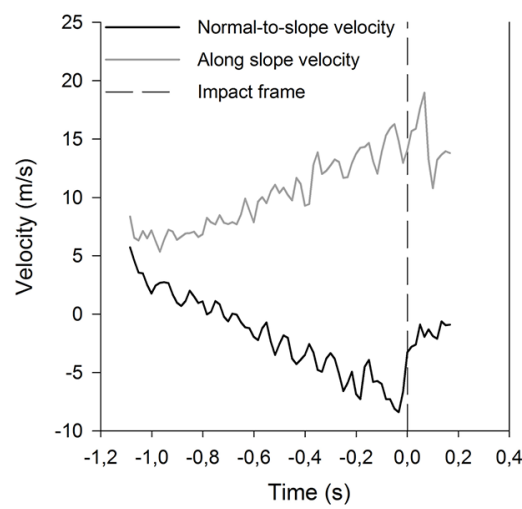

Impact 2

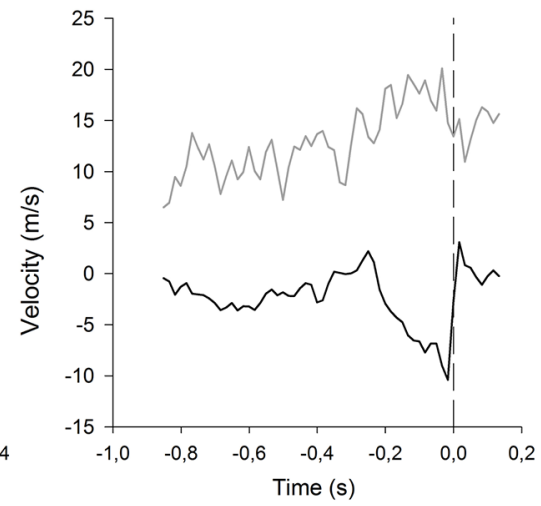

Impact 2

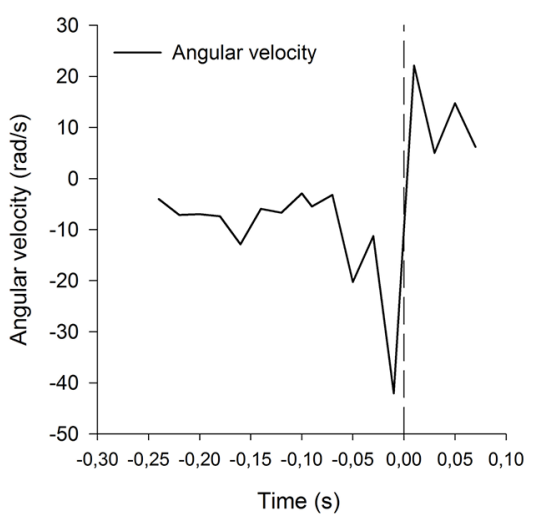

Figure 2 Case 1, impacts 1 and $2(60 \mathrm{~Hz})$. Linear velocity $(\mathrm{m} / \mathrm{s})$ of case 1, impact 1 and linear velocity $(\mathrm{m} / \mathrm{s})$ and angular velocity (rad/s) of case 1 , impact 2. 
Furthermore, we investigated the validity of our velocity estimates. We therefore calculated the vertical and horizontal velocities, and the acceleration of the skier's pelvis during flight, to see if it complied with the laws of physics. For these analyses, we assumed that the vertical axis of the video image was aligned with the true vertical axis. We performed three separate digitising trials of the pelvis only during the flight phases and fitted a linear regression line for the mean velocity of the pelvis for the flight phases of two cases to estimate the acceleration. For the digitisation of the pelvis, it was possible to perform the ski measurement and the calibration in the same frame. The calibration frame was aligned with the video image. The remaining cases either did not have a flight phase or had a flight phase where we did not have a sagittal view. We reported the root mean square error $(\mathrm{m} / \mathrm{s})$ from the regression line of the flight phases of the two eligible cases in both the vertical and horizontal directions.

\section{Head impact angle}

The impact angle is defined as the angle between the head velocity vector immediately prior to impact and the slope at the frame of impact.

\section{Angular kinematic analysis}

For four cases (cases 1, 2, 4 and 7), it was possible to measure the sagittal plane angular movement of the head/helmet/ neck unit. We measured the sagittal plane angular velocity of the head/helmet/neck unit frame by frame, from at least 10 frames preimpact to at least five frames postimpact, using an angle measurement software (MB Ruler V.5.3, Markus BaderMB-Softwaresolutions). We aligned the MB Ruler visually with an estimated alignment from the chin to the estimated midpoint of the top of the helmet on a frame-by-frame basis. We did three trials for each case and we reported the mean angular velocity \pm SD. We calculated the root mean square error of the three trials of the angular measurement.

Angular velocity was estimated as the change in angle between two frames divided by the time interval. The angular velocity data were not filtered. To estimate the change in angular velocity, we used the lowest negative point of the preimpact angular velocity and the peak of the postimpact angular velocity (maximally four frames ( $80 \mathrm{~ms}$ or less) before and after the impact) (figure 2).

\section{Injury severity}

The injury registration in the FIS ISS also covers the OWG. The FIS ISS classifies injury severity according to the duration of absence from training and competition as: slight (no absence), minimal (1-3 days), mild (4-7 days), moderate (8-28 days) and severe (>28 days). ${ }^{13}$ This classification of injury severity is an operational injury definition within the FIS ISS (where all injuries and not only head/face injuries are registered), and therefore not a head injury specific definition of severity.

\section{RESULTS}

Case 7 complied with the new FIS helmet rule at the time of injury (ASTM F2040 (class A) and EN 1077 and additional EN 1077 test of $6.8 \mathrm{~m} / \mathrm{s}$ ) while cases 1 through 6 complied with the previous helmet rule (ASTM F2040 (class A) or EN 1077) (table 1). In all seven cases, the helmet was retained on the head during the crash.

In six cases, the primary diagnosis was concussion, and in one case the primary diagnosis was an ACL injury combined with a concussion (table 1).

\section{Gross head impact injury mechanisms}

With regard to injury mechanisms, in seven impacts the athletes pitched backwards (figures 3 and 4), and in two impacts the athletes pitched forward or backward in a spiralling motion (figure 5). The impact locations on the helmet were to the back of the helmet $(n=5)$, to the top of the helmet $(n=2)$ and to the side $(n=2)$. Please see figures 3-5 for image sequences illustrating examples of the injury situations, and for descriptions of the gross injury mechanisms. Please see videos of the seven head impact injury cases provided in the manuscript supplementary video files $1-7$.

\section{Linear velocity}

The mean normal to slope preimpact velocity of the nine head impacts was $8.1 \pm 0.6 \mathrm{~m} / \mathrm{s}$ (range $1.9 \pm 0.8$ to $12.1 \pm 0.4 \mathrm{~m} / \mathrm{s}$ ) (table 2). The nine head impacts had a mean normal to slope velocity change of $9.3 \pm 1.0 \mathrm{~m} / \mathrm{s}$ (range $5.2 \pm 1.1$ to $13.5 \pm 1.3 \mathrm{~m} / \mathrm{s}$ ) and a mean along slope velocity change of $-1.3 \pm 0.7 \mathrm{~m} / \mathrm{s}$ (velocity decrease), with a range from $-4.2 \pm 0.7 \mathrm{~m} / \mathrm{s}$ (velocity decrease) to $+2.9 \pm 0.7 \mathrm{~m} / \mathrm{s}$ (velocity increase) (table 2 ).

\section{Angular velocity}

All cases displayed sagittal plane peak head angular velocity immediately prior to impact. The mean angular velocity change was $43.3 \pm 2.9 \mathrm{rad} / \mathrm{s}$ (range $21.2 \pm 1.5$ to $64.2 \pm 3.0 \mathrm{rad} / \mathrm{s}$ ) (table 2 ).

\section{Head impact angle}

The mean angle between the head velocity vector prior to impact relative to the slope at the frame of impact was $32^{\circ}$ (range $6^{\circ}$ to $\left.78^{\circ}\right)$.

\section{Error assessment}

It was possible to perform separate digitising trials of the pelvis during the flight phase for two cases (cases 1 and 3), where we could estimate vertical and horizontal velocities and acceleration.

Table 1 Description of the seven head impact injury cases

\begin{tabular}{|c|c|c|c|c|c|c|c|}
\hline & Case 1 & Case 2 & Case 3 & Case 4 & Case 5 & Case 6 & Case 7 \\
\hline Sex & Male & Female & Male & Male & Female & Female & Male \\
\hline Diagnosis & Concussion & Concussion & $\begin{array}{l}\mathrm{ACL} \text { injury, } \\
\text { concussion }\end{array}$ & Concussion & Concussion & Concussion & Concussion \\
\hline Severity (absence) & $8-28$ days & 4-7 days & $>28$ days & 4-7 days & $>28$ days & 4-7 days & $>28$ days \\
\hline Season of injury & $2009 / 2010$ & $2009 / 2010$ & $2008 / 2009$ & $2008 / 2009$ & $2006 / 2007$ & $2007 / 2008$ & $2014 / 2015^{*}$ \\
\hline Discipline & Super-G & Downhill & Super-G & Downhill & Downhill & Downhill & Super-G \\
\hline Competition & $\begin{array}{l}\text { Olympic Winter } \\
\text { Games }\end{array}$ & $\begin{array}{l}\text { Olympic Winter } \\
\text { Games }\end{array}$ & World Cup & World Cup & World Cup & World Cup & World Cup \\
\hline
\end{tabular}

${ }^{*}$ Complied with new International Ski Federation (FIS) helmet rule at time of injury (ASTM F2040 (class A) and EN 1077 and additional EN 1077 test of 6.8 m/s). 


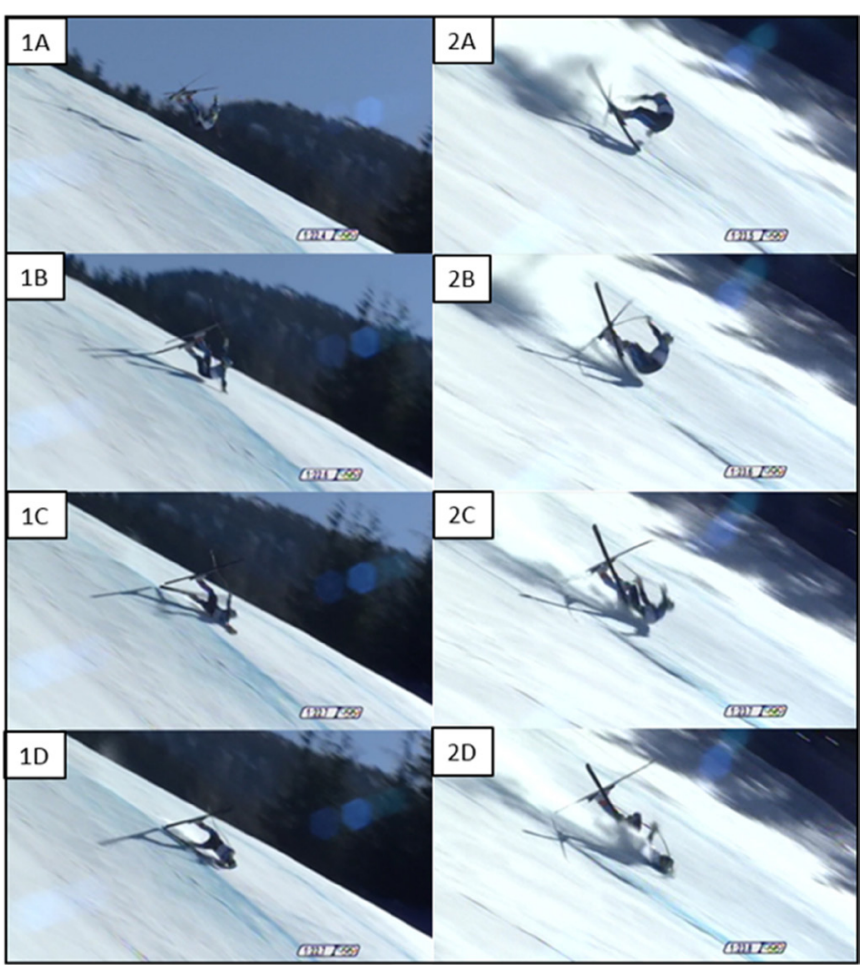

Figure 3 Case 1, impacts 1 and $2(60 \mathrm{~Hz})$. Key crash events (impact 1: $1 A-D)$ : the athlete pitches backwards and rolls sideward to the left on impact with the snow. Key crash events (impact 2: 2A-D): the athlete pitches backwards and rolls on impact with the snow.

Acceleration due to gravity is $9.81 \mathrm{~m} / \mathrm{s}^{2}$, and is therefore the target value for our vertical acceleration estimates. The vertical acceleration was 10.5 and $8.7 \mathrm{~m} / \mathrm{s}^{2}$, and the root mean square error was 0.60 and $1.4 \mathrm{~m} / \mathrm{s}$ for cases 1 and 3, respectively. Our target measure for the horizontal component of the gravitational acceleration is $0 \mathrm{~m} / \mathrm{s}^{2}$. The horizontal acceleration was 0.7 and $-0.2 \mathrm{~m} / \mathrm{s}^{2}$, and the root mean square error in the horizontal direction was 0.9 and $2.9 \mathrm{~m} / \mathrm{s}$ for cases 1 and 3, respectively.

The mean root mean square error of the three digitising trials of the helmet position in the normal to slope direction was $2.5 \mathrm{~cm}$, and in the along slope direction $3.0 \mathrm{~cm}$ for the nine head impacts.

The mean root mean square error of the three trials of the angular measurement of the helmet was $3^{\circ}$.

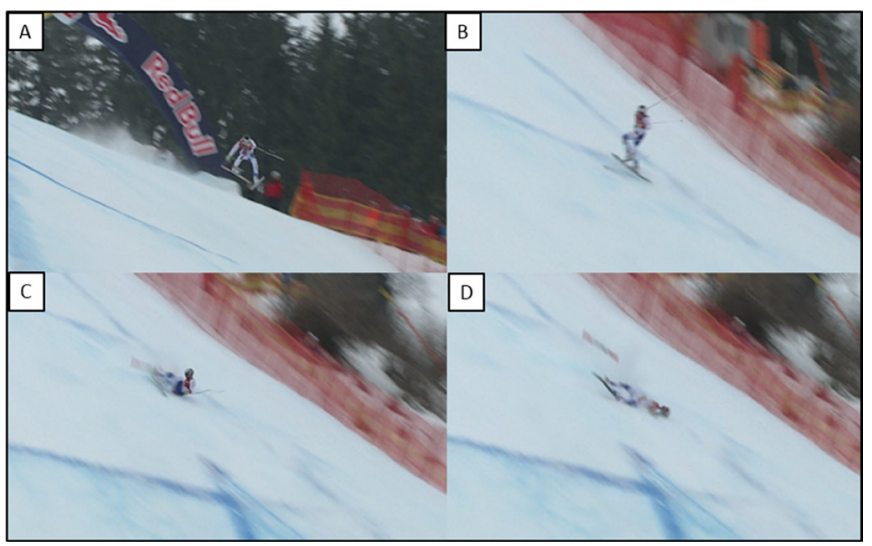

Figure 4 Case $7(50 \mathrm{~Hz})$. Key crash events $(A-D)$ : the athlete pitches backwards and rolls to the left on impact with the snow.

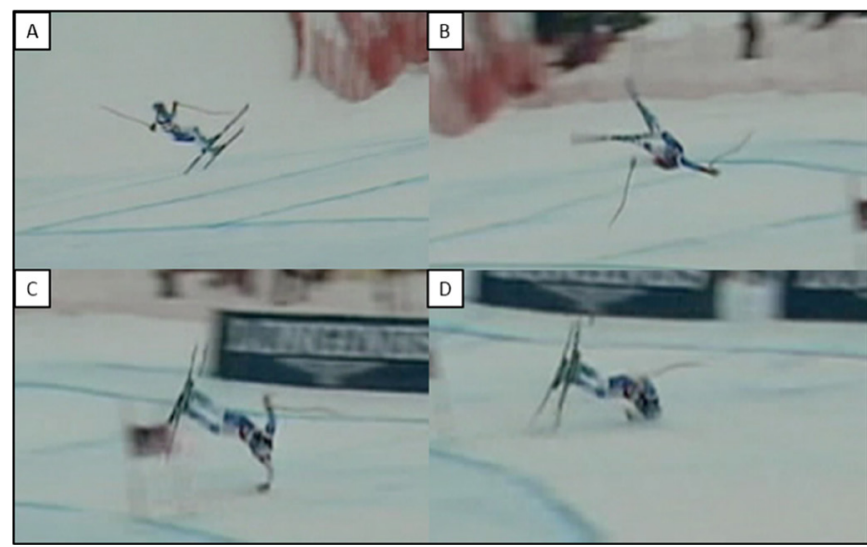

Figure 5 Case $3(50 \mathrm{~Hz})$. Key crash events (A-D): the athlete pitches forward in a spiralling motion and dives head first into the snow.

\section{DISCUSSION}

This is the first study to reconstruct a series of real-life head impact injury cases in WC alpine skiing. In seven of the nine head impacts, the estimated normal to slope preimpact velocity was greater than the prevailing minimum requirements at the time of the incidents of $5.4 \mathrm{~m} / \mathrm{s}$ (EN 1077) and $6.2 \mathrm{~m} / \mathrm{s}$ (ASTM F2040), and also higher than the current strictest FIS helmet testing rule of $6.8 \mathrm{~m} / \mathrm{s}$ (EN 1077-additional test) for alpine giant slalom, super-G and downhill. The change in head velocity from preimpact to postimpact in the normal to slope direction ranged from $5.2 \pm 1.1$ to $13.5 \pm 1.3 \mathrm{~m} / \mathrm{s}$. Only one head impact had a normal to slope preimpact velocity below the previous FIS helmet testing rule of $5.4 \mathrm{~m} / \mathrm{s}$.

\section{Gross injury mechanisms}

We identified a gross injury mechanism where the athlete pitched backward and impacted the back of the helmet in five of nine head impacts (figures 3: 2A-D and 4). This mechanism is characterised by the athlete landing onto his/her buttocks and pitching backwards onto his/her back, followed by impacting the back of the helmet (figures 3:2A-D and 4). This is similar to a slapback mechanism in freestyle skiers ${ }^{14}$ or a back-edge catch mechanism in snowboarders, where athletes also pitch backwards, impacting the back of the helmet. ${ }^{15}$

We observed two additional gross injury mechanisms, where the athletes pitched either forward or backward in spiralling motions, impacting the top part of the helmet (case 3, case 6-impact 1, figure 5) or situations where the athlete landed partly sideways, impacting the snow with the side of the helmet (case 1 -impact 1 , case 6 -impact 2 , figure $3: 1 \mathrm{~A}-\mathrm{D}$ ).

\section{Linear kinematics and implications for helmet standards}

The normal to slope preimpact velocity, which relates most directly to the height specified in helmet drop tests, was in seven of nine helmet impacts higher than the prevailing requirements at the time of the incidents $(5.4 \mathrm{~m} / \mathrm{s}$ (EN 1077) or $6.2 \mathrm{~m} / \mathrm{s}$ (ASTM F2040)) and the current FIS helmet rule of EN 1077 plus ASTM F2040 plus $6.8 \mathrm{~m} / \mathrm{s}$ impact test.

As expected, on a low friction surface such as snow/ice, the along slope velocity change was relatively insignificant compared with the normal to slope velocity change, despite velocities of up to $28 \mathrm{~m} / \mathrm{s}$ in our study.

We have only analysed 21\% (7/33) of the head injury cases in this athlete population during the 2006-2015 time period, and this sample size is too small to generalise our findings. There 
Table 2 Estimated linear velocity of the digitised helmet points including the change in head velocity of cases 1-7 (nine impacts), and estimated angular velocity of cases 1, 2, 4 and 7 (five impacts) \pm SD of the three trials. Negative linear velocity refers to downward movement (towards the slope) in the normal to slope direction, while positive velocity refers to a rebound (upward) movement. Negative angular velocity refers to a head rotation towards extension while positive angular velocity refers to a head rotation towards flexion. A negative velocity change in the along slope direction indicates a decrease in velocity from preimpact to postimpact, while a positive along slope velocity change indicates a velocity increase

\begin{tabular}{|c|c|c|c|c|}
\hline Case number & Analysed frame rate $(\mathrm{Hz})$ & Preimpact velocity $( \pm S D)$ & Postimpact velocity ( \pm SD) & Change in velocity $( \pm S D)$ \\
\hline \multicolumn{5}{|c|}{ Normal to slope velocity $(\mathrm{m} / \mathrm{s})$} \\
\hline 1-impact 1 & 60 & $-8.4(0.6)$ & $-0.9(0.4)$ & $7.5(0.7)$ \\
\hline 1-impact 2 & 60 & $-10.4(0.7)$ & $3.1(0.6)$ & $13.5(1.3)$ \\
\hline 2 & 50 & $-8.3(0.4)$ & $0.4(0.3)$ & $8.7(0.1)$ \\
\hline 3 & 50 & $-1.9(0.8)$ & $3.3(1.0)$ & $5.2(1.1)$ \\
\hline 4 & 50 & $-5.6(0.1)$ & $3.1(0.1)$ & $8.7(0.1)$ \\
\hline 5 & 50 & $-8.2(1.1)$ & $0.0(0.9)$ & $8.2(1.9)$ \\
\hline 6-impact 1 & 50 & $-7.7(0.7)$ & $3.5(2.2)$ & $11.2(2.1)$ \\
\hline 6-impact 2 & 50 & $-10.1(0.6)$ & $-1.8(0.3)$ & $8.3(1.0)$ \\
\hline 7 & 50 & $-12.1(0.4)$ & $0.4(0.4)$ & $12.5(0.3)$ \\
\hline \multicolumn{5}{|c|}{ Along slope velocity $(\mathrm{m} / \mathrm{s})$} \\
\hline 1-impact 1 & 60 & $14.8(0.7)$ & $17.7(0.3)$ & $+2.9(0.7)$ \\
\hline 1-impact 2 & 60 & $14.8(0.2)$ & $15.1(0.4)$ & $+0.3(0.3)$ \\
\hline 2 & 50 & $1.9(0.4)$ & $0.0(0.3)$ & $-1.9(0.4)$ \\
\hline 3 & 50 & $18.7(1.1)$ & $15.8(0.8)$ & $-2.9(1.5)$ \\
\hline 4 & 50 & $27.9(1.3)$ & $27.4(0.9)$ & $-0.5(0.6)$ \\
\hline 5 & 50 & $16.9(0.8)$ & $16.6(0.3)$ & $-0.3(0.7)$ \\
\hline 6-impact 1 & 50 & $10.2(0.1)$ & $6.5(0.8)$ & $-3.7(0.7)$ \\
\hline 6-impact 2 & 50 & $14.9(0.5)$ & $13.9(0.7)$ & $-1.0(0.5)$ \\
\hline 7 & 50 & $17.6(0.2)$ & $13.4(0.5)$ & $-4.2(0.7)$ \\
\hline \multicolumn{5}{|c|}{ Angular velocity (rad/s) } \\
\hline 1—impact 1 & 60 & $-10.5(3.7)$ & $18.0(3.2)$ & $28.5(3.5)$ \\
\hline 1-impact 2 & 60 & $-42.1(0.5)$ & $22.1(2.9)$ & $64.2(3.0)$ \\
\hline 2 & 50 & $-42.8(0.3)$ & $15.8(0.9)$ & $58.6(1.0)$ \\
\hline 4 & 50 & $-18.5(1.2)$ & $2.7(2.1)$ & $21.2(1.5)$ \\
\hline 7 & 50 & $-24.3(4.8)$ & $19.6(1.2)$ & $43.9(5.6)$ \\
\hline
\end{tabular}

were no skull fractures or severe traumatic brain injuries (TBIs) reported among our seven cases. However, in three of the seven cases, the absence due to injury was over 28 days. Importantly though, in case 3 , where the athlete had the lowest estimated preimpact velocity $(1.9 \pm 0.8 \mathrm{~m} / \mathrm{s})$, the athlete suffered an ACL rupture as his primary diagnosis, and the absence ( $>28$ days) relates to his ACL injury. We do not know his concussion-related absence. We can therefore only classify two cases (cases 5 and 7) as severe concussions as defined by the FIS ISS. ${ }^{113}$ In both of these cases, the normal to slope preimpact velocity was above the helmet testing velocity at the time of the injury. Case 7 obtained a severe injury with a helmet complying with the new FIS helmet rule $(6.8 \mathrm{~m} / \mathrm{s})$. The preimpact velocity in this incident was $12.1 \pm 0.4 \mathrm{~m} / \mathrm{s}$. Case 5 had a helmet complying with the previous FIS helmet rule $(5.4$ or $6.2 \mathrm{~m} / \mathrm{s}$ ) and the preimpact velocity in this incident was $8.2 \pm 1.1 \mathrm{~m} / \mathrm{s}$.

The absence due to injury was 4-7 days in three cases (cases 2, $4,6)$, indicating that the helmets provided adequate protection of the head in these cases. In these cases, the helmets complied with the previous helmet rule $(5.4$ or $6.2 \mathrm{~m} / \mathrm{s})$. The preimpact velocities in these cases ranged from 5.6 to $10.1 \mathrm{~m} / \mathrm{s}$, and were therefore above the minimum helmet test speed $(5.4 \mathrm{~m} / \mathrm{s})$ at the time of the injury.

Previous reconstructive studies of head impact kinematics in snow sports have reported similar results to our findings, with normal to slope head impact velocities of $8.11,7.8 \pm 1.7$ and $11 \mathrm{~m} / \mathrm{s}^{16-18}$ In line with these results, we previously reported that helmet preimpact velocities in four cases of snowboarding backedge catches and freestyle head impacts ranged from $7.0 \pm 0.2$ to $10.5 \pm 0.5 \mathrm{~m} / \mathrm{s}$ in the normal to slope direction, with normal to slope velocity changes ranging from $8.4 \pm 0.6$ to $11.7 \pm 0.7 \mathrm{~m} / \mathrm{s}^{19}$

Our results, however, do not indicate a need to change the helmet impact velocities in FIS-mandated helmet rules in alpine skiing at present. This is partly because our study is limited by the sample size and a lack of information concerning the helmet models used. In addition, we lack information about the relationship between real-world head impacts onto snow and ice, and laboratory head impacts during helmet testing procedures. We have in a previous paper extensively discussed issues relating to the equivalence between real-world impacts and laboratory helmet tests. ${ }^{19}$ We reiterate that the relationship between real head impacts on snow and laboratory testing on rigid anvils must be investigated further by performing helmet testing outside on real WC prepared snow and ice.

\section{Angular kinematics and implications for helmet standards}

In five of the nine situations, the skier experienced a backward pitching fall with a large change in head angular velocity $(21.2 \pm 1.5$ to $64.2 \pm 3.0 \mathrm{rad} / \mathrm{s})$ during impact. This may have important implications for head injury research, since rotationally induced strain deformation on the brain tissue can cause concussive trauma. ${ }^{20}$ 
To prevent head and brain injuries, the helmet's ability to minimise rebound is important, and an optimum helmet design would reduce the rebound velocity to zero. ${ }^{21}$ Our results identified that the head underwent high angular velocity changes during impact. Changes in head angular velocity will result in head angular acceleration. Both linear and angular velocity changes demonstrated that there was a rebound phase immediately postimpact, which might not be anticipated in an impact with soft snow.

In all of the five impacts where angular velocity could be obtained, there was an angular rebound movement, indicated by a positive angular velocity postimpact (table 2). Only in case 1-impact 1 and case 6-impact 2 was there no detectable linear velocity rebound movement. However, case 1 -impact 1 had substantial angular rebound, while we could not measure the angular velocity of case 6 . The severity of the injuries in these cases was 8-28 days (case 1) and 4-7 days (case 6). It is, however, difficult to interpret the implications of experiencing rebound compared with no rebound in our study from such a limited amount of cases. The impact angles of the head velocity vector relative to the slope at the frame of impact were between $6^{\circ}$ and $78^{\circ}$. Among the five cases where angular velocity could be estimated, we observed that the cases with the greatest impact angle seemed to have the greatest angular velocity change. In these situations, the athletes pitched backward and impacted the back of the helmet (case 1-impact 2 and case 2).

\section{Limitations}

The study sample was derived systematically from a prospective collection of videos from a defined injured athlete population. This process produced only a limited number of cases with a sagittal view of the crash on video. Therefore, these findings could be biased, and a more comprehensive video analysis study including all alpine head injury cases from the FIS ISS in all planes of movement is needed to assess the representativeness of our nine analysed head impacts.

Angular velocity changes may occur in all three planes of movement. We are limited to estimating angular velocity change in the sagittal plane. We do not have information about snow properties, muscle activation (such as neck muscle contraction) or force transfer from the body or neck to the head at impact, which makes it difficult to consider the consequence of the impact angles.

Both the helmet and the snow impact surface may contribute to rebound. As we do not have information about the snow properties in our cases, we do not know how this influenced the rebound motion. Future helmet standards could potentially address these issues. ${ }^{19}$

Comparing our seven injury cases with similar control cases (videos where an athlete obtained a head impact with no diagnosed head injury) would potentially be helpful in identifying if there were any differences in the impact characteristics in injury versus non-injury cases. However, identifying suitable control videos is not possible, since we cannot be certain that the athletes did not sustain a head injury, even if no injury was recorded through the FIS ISS.

Television footage will typically become blurry when there are large velocity changes. Coupled with limited frame rates $(50$ and $60 \mathrm{~Hz}$ ) and snow spray, this makes it challenging to estimate impact kinematics accurately. We attempted to optimise the accuracy by performing three digitising trials of the linear velocity and angular velocity measures and reporting the mean. The mean root mean square error of the digitised helmet position was under $3 \mathrm{~cm}$, indicating that the intrarater digitising was consistent between trials.

The main limitations in our velocity analyses are from snow spray, camera blur and limited temporal resolution. Blur is mainly a problem in the few frames immediately after impact. Hence, it was not possible to accurately measure the kinematics during the short duration of the impact. Image quality until the last frame before impact allowed for accurate visualisation of helmet reference points and estimation of head velocity immediately before impact, as verified by the estimates of vertical acceleration during flight.

We also cannot be certain that the video footage is aligned with the true vertical axis. In response, we partly verified this by reporting the vertical acceleration and root mean square error during the flight phase. The root mean square error during the flight phase of cases 1 and 3 was 0.60 and $1.4 \mathrm{~m} / \mathrm{s}$ from the regression line, indicating a low error of our vertical velocity estimates.

The estimated vertical acceleration during the flight phases of cases 1 and 3 was close to the gravitational acceleration constant of $9.8 \mathrm{~m} / \mathrm{s}^{2}$, and the estimated horizontal acceleration was close to $0.0 \mathrm{~m} / \mathrm{s}^{2}$, which indicates that the accuracy of our vertical and horizontal velocity estimates was reasonable. The relatively accurate results relating to the vertical acceleration measurements most likely arose because of the restrictive case inclusion and exclusion criteria.

To filter the linear velocity, we chose a $15 \mathrm{~Hz}$ cut-off frequency because lower frequencies would oversmooth the peak velocity estimate. Through different filtering trials, we identified that a $7 \mathrm{~Hz}$ cut-off could underestimate the velocity change of the impact by approximately $28 \%$ compared with a $15 \mathrm{~Hz}$ cut-off. On average, the $15 \mathrm{~Hz}$ spline filter peak velocity estimates differed from those of simple differentiation by only $3 \%$.

We chose not to filter the angular velocity signal, considering that this would give the most realistic estimate of the actual angular velocity. Although we could have used an algorithm including more time points to estimate velocity (eg, a Butterworth or spline filter), we chose to use a simple differentiation scheme because there were large changes in head orientation between frames, which progressed towards head impact (up to $40^{\circ}$ differences between two frames). Therefore, due to the limited temporal resolution, and with a root mean square error of only $3^{\circ}$, we would argue that a simple differentiation scheme will likely provide the best estimates of the true velocities, since other methods would likely underestimate the maximal velocity immediately prior to the impact. We are aware that small measurement errors could potentially generate large errors in the estimates, but the angular velocity curves, showing a steady increase in angular velocity towards impact, indicate that our estimates are realistic.

However, some caution and interpretation are required if these angular velocity change estimates were to be compared with angular velocity measured in controlled experiments using defined signal conditioning methods.

\section{CONCLUSION}

In seven of nine head impacts, the estimated normal to slope preimpact velocity was higher with regard to the prevailing FIS helmet rule at the time of injury and higher than the current strictest FIS helmet rule of $6.8 \mathrm{~m} / \mathrm{s}$. There were two severe concussions among the seven cases. However, as we do not have information about the snow properties in these incidents, it is not possible to relate our findings to laboratory helmet testing 
standards. We identified that the head underwent a considerable angular velocity change during the head impact combined with a rebound motion, which may contribute to brain injury. The influence of the snow impact surface and the helmet foam liner characteristics require further research in order to optimise helmet performance and athlete protection.

\section{What are the findings?}

- This is the first study to describe the gross head impact biomechanics, and to report head impact velocities of seven real concussive events among International Ski Federation (FIS) World Cup alpine skiers.

- In seven of nine head impacts, the estimated normal to slope preimpact velocity was higher than the prevailing FIS helmet rule $(5.4$ and $6.2 \mathrm{~m} / \mathrm{s})$ at the time of injury and higher than the current strictest FIS helmet rule of $6.8 \mathrm{~m} / \mathrm{s}$.

- The head may undergo a considerable angular velocity change during the head impact which may contribute to brain injury, and may be influenced by the snow/ice interface and the helmet foam liner characteristics.

\section{How might it impact on clinical practice in the future?}

- This study provides important information about real-life head impact velocities and gross head impact biomechanics in alpine skiing.

- Information about real-life head impact velocities and accurate descriptions of the mechanisms of head injuries are important considerations if helmet testing is to be developed and evaluated with regard to realistic impact conditions.

- Future laboratory and field-based studies should examine snow properties quantitatively and perform helmet impact tests on real-life snow and ice.

Acknowledgements We thank the World Cup athletes, coaches and medical team personnel who participated in this study, and the International Ski Federation staff and officials for practical support. We thank Professor Lars Engebretsen and $\mathrm{Dr}$ Torbjørn Soligard from the IOC for assistance in obtaining videos from the Olympic Winter Games.

Contributors All authors have made substantial contributions to all of the following: the conception and design of the study, or acquisition of data, or analysis and interpretation of data, drafting the article or revising it critically for important intellectual content, and final approval of the version to be submitted.

Funding The Oslo Sports Trauma Research Center has been established at the Norwegian School of Sport Sciences through generous grants from the Royal Norwegian Ministry of Culture, the South-Eastern Norway Regional Health Authority, the International Olympic Committee, the Norwegian Olympic Committee and Confederation of Sport, and Norsk Tipping AS. The FIS Injury Surveillance System is supported by the International Ski Federation and was established through a generous grant from DJO.

\section{Competing interests None declared.}

Patient consent Detail has been removed from this case description/these case descriptions to ensure anonymity. The editors and reviewers have seen the detailed information available and are satisfied that the information backs up the case the authors are making.

Ethics approval The study was reviewed by the Regional Committee for Medical Research Ethics, South-Eastern Norway Regional Health Authority, Norway.

Provenance and peer review Not commissioned; externally peer reviewed.

(C) Article author(s) (or their employer(s) unless otherwise stated in the text of the article) 2018. All rights reserved. No commercial use is permitted unless otherwise expressly granted.

\section{REFERENCES}

1 Flørenes TW, Bere T, Nordsletten L, et al. Injuries among male and female World Cup alpine skiers. Br J Sports Med 2009:43:973-8.

2 Bere T, Flørenes TW, Nordsletten L, et al. Sex differences in the risk of injury in World Cup alpine skiers: a 6-year cohort study. Br J Sports Med 2014;48:36-40.

3 FIS helmet rule 2013/14 updated 2013. 2013. http://www.fis-ski.com/data/document/ 121107-helmet-rule-final.pdf

4 International Ski Federation. FIS Specifications for competition equipment and commercial markings. 2016. http://www.fis-ski.com/mm/Document/documentlibrary/ Marketing/04/30/53/Competitionequipment_1617_11072016_clean_English.pdf (accessed 29 Nov 2016).

5 Standardisation CSN. EN 1077: 2007. Helmets for alpine skiers and snowboarders. 2007. https://www.en-standard.eu/csn-en-1077-helmets-for-alpine-skiers-and-sn owboarders/?gclid=CNv2jaW229QCFQqBsgodEy8Dpg (accessed 26 Jun 2017).

6 ASTM International. Standardization ASTM F2040-11, Standard Specification for Helmets Used forRecreational Snow Sports. West Conshohocken, PA: ASTM International, 2011

7 Connor TA, Meng S, Zouzias D. Head protection: a European training network for Advanced Designs in Safety. 2016. http://www.heads-itn.eu/pdfs/Helmets_Standard_ Evaluation.pdf (accessed 26 Jun 2017).

8 McIntosh AS, Andersen TE, Bahr R, et al. Sports helmets now and in the future. $\mathrm{Br} J$ Sports Med 2011;45:1258-65.

9 McIntosh AS, Patton DA. Boxing headguard performance in punch machine tests. $\mathrm{Br} J$ Sports Med 2015;49:1108-12.

10 McIntosh AS, Lai A, Schilter E. Bicycle helmets: head impact dynamics in helmeted and unhelmeted oblique impact tests. Traffic Inj Prev 2013;14:501-8.

11 Flørenes TW, Nordsletten L, Heir S, et al. Injuries among World Cup ski and snowboard athletes. Scand J Med Sci Sports 2012;22:58-66.

12 Woltring HJ. A Fortran package for generalized, cross-validatory spline smoothing and differentiation. Adv Eng Software 1986;8:104-13.

13 Flørenes TW, Nordsletten L, Heir S, et al. Recording injuries among World Cup skiers and snowboarders: a methodological study. Scand J Med Sci Sports 2011;21:196-205.

14 Mecham MD, Greenwald RM, Macintyre JG, et al. Incidence and Severity of Head Impact during Freestyle Aerial Ski Jumping. J Appl Biomech 1999;15:27-35.

15 Nakaguchi H, Tsutsumi K. Mechanisms of snowboarding-related severe head injury: shear strain induced by the opposite-edge phenomenon. J Neurosurg 2002;97:542-8

16 Bailly N, Llari M, Donnadieu T, et al. Head impact in a snowboarding accident. Scand $\int$ Med Sci Sports 2017;27:964-74

17 Richards D, Carhart M, Scher I, et al. Head Kinematics During Experimental Snowboard Falls: Implications for Snow Helmet Standards. J ASTM Int 2008:5:101406.

18 Yamazaki J, Gilgien M, Kleiven S, et al. Analysis of a severe head injury in World Cup alpine skiing. Med Sci Sports Exerc 2015;47:1113-8.

19 Steenstrup SE, Mok KM, McIntosh AS, et al. Head impact velocities in FIS World Cup snowboarders and freestyle skiers: Do real-life impacts exceed helmet testing standards? Br J Sports Med 2017 (Epub ahead of print 10 Jul 2017).

20 Ommaya AK, Gennarelli TA. Cerebral concussion and traumatic unconsciousness. Correlation of experimental and clinical observations of blunt head injuries. Brain 1974;97:633-54.

21 Newman J. Biomechanics of Head Trauma. In: Nahum AM, Melvin JW, eds. Accidental Injury Biomechanics And Prevention. United States of America: Springer Science + Business media, Inc, 2002 